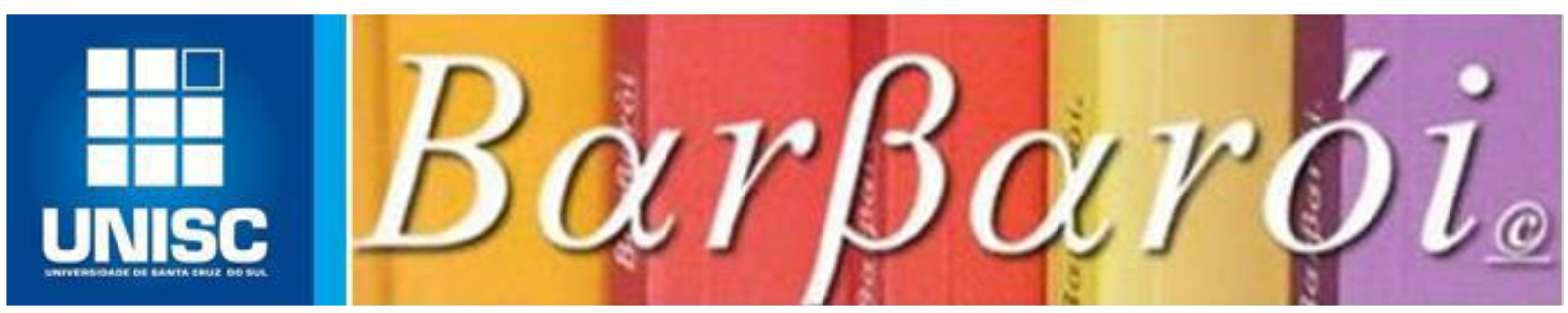

\title{
O TRABALHO DO ASSISTENTE SOCIAL E AS ESTRATÉGIAS DE INTERVENÇÃO NOS SERVIÇOS DE SAÚDE DE MÉDIA COMPLEXIDADE EM TIMON (MA)
}

DOI: http://dx.doi.org/10.17058/barbaroi.v0i0.14833

\author{
Violêta Maria da Silva Nolêto \\ Universidade Federal do Piaui - UFPI - Brasil \\ Edna Maria Goulart Joazeiro \\ Universidade Federal do Piauí - UFPI - Brasil

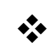

\section{Resumo}

O presente artigo apresenta uma análise sobre o trabalho do assistente social e as estratégias de intervenção implementadas no cotidiano dos serviços de saúde de Média Complexidade no município de Timon, Estado do Maranhão, assim como busca compreender a questão social e a vulnerabilidade social no trabalho do assistente social no referido município. O estudo é um recorte da dissertação de Mestrado defendida no Programa de Pós-Graduação em Políticas Públicas da Universidade Federal do Piauí (UFPI). No percurso metodológico foi utilizada a pesquisa qualitativa, com análise de literatura, pesquisa documental e de campo, através de uso de grupos focais, tendo como participantes cinco assistentes sociais que atuam em cinco instituições públicas de saúde de Média Complexidade do município no SUS. No estudo, as assistentes sociais revelaram em suas narrativas que, diariamente, são chamadas a intervir num espaço, marcado por múltiplas formas de saberes, contudo, são profundamente tensionadas pela ampliação da demanda de atenção especializada em saúde, cuja oferta está subdimensionada em relação à disponibilidade de vagas de consultas, exames especializados e de leitos hospitalares. O estudo revelou que o trabalho da assistente social nesse nível de complexidade, está marcado pela dinâmica de tentar produzir acessos e fluxos mais resolutivos no atendimento da população usuária nas instituições de saúde e na Rede, buscando imprimir dinamicidade aos processos de fruição do direito à atenção à saúde na esfera do SUS.

Palavras-chave: Trabalho. Questão Social. Atenção Secundária.

\section{Introdução}

No estudo, analisamos o trabalho do assistente social e as estratégias de intervenção implementadas no cotidiano dos serviços de saúde de Média Complexidade no município de Timon-MA. O presente artigo é um recorte da dissertação de Mestrado defendida no Programa 
de Pós-Graduação em Políticas Públicas da Universidade Federal do Piauí (UFPI), que tem como título "O trabalho do assistente social na saúde de Média Complexidade no município de Timon-MA: avanços e desafios da e na profissão".

O acesso universal aos serviços de saúde no Brasil passou a ser garantido a partir da promulgação da Constituição Federal de 1988, constituindo-se em um dos direitos fundamentais de cidadania. Segundo Silva et al (2017), o acesso efetivo não consiste na mera utilização dos serviços de saúde, mas corresponde à possibilidade de aproveitá-los em um cenário que permita o uso apropriado dos mesmos, no tempo adequado, para o alcance dos melhores resultados de saúde, independente do nível de complexidade demandado.

A dificuldade de acesso aos serviços de saúde de Média Complexidade no Brasil consiste em um dos principais obstáculos à efetivação da integralidade do SUS (GOMES et al, 2014). Nesse sentido, estudar o trabalho dos assistentes sociais que intervêm na saúde nesse nível de complexidade é fundamental para produzir conhecimentos relevantes para a comunidade acadêmica, profissionais e gestores de saúde, propiciando assistência à saúde à população que demanda esses serviços.

Assim, as categorias de análise que destacamos no estudo são sociedade, história, cotidiano, trabalho, território, tempo, temporalidades, memória e saúde, em virtude destas comporem uma matriz categorial que esteve presente no decorrer da construção, da análise e da fundamentação do presente estudo. Utilizou ainda o conceito de território na perspectiva de Santos (2006), ou seja, como "o lugar em que desembocam todas as ações, todas as paixões, todos os poderes, todas as forças, todas as fraquezas, isto é, onde a história do homem plenamente se realiza a partir das manifestações de sua existência” (SANTOS, 2006, p. 13).

A sociedade deve ser compreendida em sua totalidade, uma vez que ela é constituída por múltiplas dimensões, nela estando presente relações de poder, tensões, desigualdades no acesso a riqueza, potencialidades e fragilidades múltiplas, que se expressam de diferentes formas no decorrer do tempo, sendo imprescindível que o assistente social, no exercício de seu trabalho faça mediações com vistas à "decifração da realidade” (IAMAMOTO, 2008, p. 28) do meio histórico no qual está inserido. Como assinala Joazeiro (2008), nas atividades tecidas no espaço do trabalho no campo do social, pela simples observação, não é possível apreender as escolhas, as categorias de análise, nem os saberes que as movem. "Nada no trabalho é evidente" (ibid., p. 127).

Cumpre destacar que o trabalho do assistente se situa no cotidiano, portanto tem o seu lugar na história, sendo o seu fazer partícipe do processo de sua constituição. Assinala Netto (1987) que a vida cotidiana em sua insuprimibilidade ontológica não se mantém como uma Barbarói, Santa Cruz do Sul, n. 56, p.<22-43>, jan./jun. 2020 
“relação seccionada com a história. O cotidiano não se descola do histórico - antes é um dos seus níveis constitutivos" (op. cit, p. 65).

A categoria trabalho aqui analisada refere-se à perspectiva de Marx (2006), onde o trabalho é tido como uma atividade fundamental do ser humano, como categoria ontológica do ser social, que na relação entre homem e natureza, tem por objetivo transformar ambos e produzir os bens necessários à sobrevivência do homem.

A questão do tempo interpela o estudo à medida que o situa no limiar das tomadas de decisão, ou seja, o vincula ao desafio da questão do trabalho em atos na dinâmica da intervenção na vida do outro. Elias (1998) afirma que "ao examinarmos os problemas relativos ao tempo, aprendemos sobre os homens e sobre nós mesmos, muitas coisas que antes não discerníamos com clareza [...] que as teorias dominantes não permitiam apreender" (ELIAS, 1998, p. 7).

Remete, assim, à questão das múltiplas temporalidades indispensáveis para a produção de ação que seja capaz de lidar com a heterogeneidade da demanda. Em Joazeiro (2018), buscamos as quatro dimensões das temporalidades: a do relógio, a temporalidade burocrática, a ergológica, e a do cuidado (JOAZEIRO, 2018, p. 42, p. 105).

A memória foi outra categoria utilizada, segundo Bosi (2003), dentro da história cronológica, existe "outra história mais densa de substância memorativa no fluxo do tempo. A memória opera com grande liberdade escolhendo acontecimentos no espaço e no tempo, não arbitrariamente, mas porque se relacionam através de índices comuns" (op. cit., 2003, p. 11).

A categoria saúde dever ser compreendida com base na concepção ampliada de saúde, que considera os Determinantes Sociais da Saúde (DSS) ${ }^{1}$, definidos pela Organização Mundial da Saúde (OMS), como as condições sociais em que as pessoas vivem e trabalham.

A luz das categorias supracitadas, o artigo tem por objetivo analisar o trabalho do assistente social nos serviços de saúde de Média Complexidade, bem como compreender a relação entre agravos à saúde, terapêutica, questão social e a vulnerabilidade social no trabalho do assistente social no município de Timon, Estado do Maranhão.

A metodologia utilizada na pesquisa foi de natureza qualitativa (MINAYO, 2001; GIL, 2007), com análise de literatura, pesquisa documental e pesquisa de campo, desenvolvida com as técnicas de grupo focal (GATTI, 2005) e discussão em grupo (FLICK, 2009), bem como questionário (GIL, 2007) de perguntas abertas e fechadas preenchido pelas assistentes sociais

\footnotetext{
${ }^{1}$ Os Determinantes Sociais da Saúde (DSS), conforme previsto na Lei n. 8.080/90, em seu artigo $3^{\circ}$, prevê que os níveis de saúde expressam a organização social e econômica do país, tendo a saúde como determinantes e condicionantes, entre outros, a alimentação, a moradia, o saneamento básico, o meio ambiente, o trabalho, a renda, a educação, a atividade física, o transporte, o lazer e o acesso aos bens e serviços essenciais.
}

Barbarói, Santa Cruz do Sul, n. 56, p.<22-43>, jan./jun. 2020 
participantes do estudo. A pesquisa foi analisada sob a ótica do método histórico-dialético de Marx, tendo a fundamentação teórica de Iamamoto (2008, 2009); Joazeiro (2002, 2008, 2018); Mioto e Nogueira (2009); dentre outros.

O estudo teve como participantes cinco assistentes sociais que trabalham em cinco instituições públicas de saúde no SUS no nível de Média Complexidade do referido município cuja participação se deu mediante a assinatura do Termo de Consentimento Livre e Esclarecido (TCLE). A pesquisa de campo iniciou com a coleta de dados, por meio do preenchimento de questionário pelas assistentes sociais que trabalham nos referidos serviços ${ }^{2}$ e a segunda etapa se deu com a realização de dois grupos focais. No que diz respeito à ética na pesquisa, o projeto teve a apreciação da Comissão de Ética da Secretaria Municipal de Saúde de Timon (MA), tendo sido submetido e aprovado pelo Comitê de Ética em Pesquisa da Universidade Federal do Piauí (UFPI) ${ }^{3}$.

A análise e categorização do material coletado nos questionários semiabertos e as transcrições das narrativas das assistentes sociais nos grupos focais e na discussão em grupo estão em consonância com os objetivos do estudo. Nessa perspectiva, pensar as narrativas das participantes no grupo focal e na discussão em grupo, significa compreender que a tessitura desses diálogos construídos nesse espaço temporal e coletivo "são configurações mais intensas quando sobre elas incide o brilho de um significado coletivo" (BOSI, 2003, p. 11).

Na escrita do artigo, definimos a apresentação do material advindo dos questionários, dos dois grupos focais e da discussão em grupo pela identificação seguindo a seguinte orientação: identificou-se a assistente social através de $1^{\mathrm{a}}$ Assistente Social ( $\left.1^{\mathrm{a}} \mathrm{AS}\right), 2^{\mathrm{a}}$ Assistente Social ( $2^{\text {a }}$ AS), e assim, sucessivamente, seguida da natureza da fonte, se decorrente do questionário (Q), grupo focal (GF) ou discussão em grupo (DG). Com o objetivo de preservar a identidade das assistentes sociais da pesquisa optou-se pelo uso do critério supracitado com base na ordem de aceite de participação da pesquisa.

\section{O trabalho do assistente social nos serviços de saúde de Média Complexidade}

Na constância da realização dos grupos focais as cinco assistentes sociais se referiram continuamente à dinâmica do dia a dia que se instaura no trabalho nas instituições de saúde de Média Complexidade. Ao tentarem demarcar em que consiste o seu trabalho, tema proposto

\footnotetext{
${ }^{2}$ Unidade de Saúde Dr. Antônio Martins Albuquerque Pedreira (Policlínica), Centro de Atenção Integrada à Saúde da Mulher (CAISM), Centro Integrado de Atendimento Educacional Especializado Maria do Carmo Viana Neiva, Hospital Municipal do Parque Alvorada (HPA) e Centro de Atenção Especializada e Materno Infantil (CAEMI). ${ }^{3}$ Parecer $N^{\circ}$. 3.152.353 e com CAAE No. 05277219.8.0000.5214, aprovado na reunião do CEP-UFPI no dia 18 de fevereiro de 2019.
}

Barbarói, Santa Cruz do Sul, n. 56, p.<22-43>, jan./jun. 2020 
para o primeiro grupo focal, mas que, em virtude da centralidade dessa temática para as participantes do estudo, foi por elas retomado no decorrer dos demais grupos focais. As participantes afirmaram

Então, você perguntou o trabalho, mas eu queria... o que eu posso dizer assim para você? Eu viabilizo direitos e encaminho a eles, se a gente for olhar, tudo é direito, mas o meu principal trabalho é esse.

Fragmento da narrativa da $2^{\mathrm{a}} \mathrm{AS}-\mathrm{GF} 1$.

O que eu vejo é isso, não a demanda, [mas] são várias. Os pacientes dão entrada em busca de atendimento, [...], tanto social como da equipe.

Fragmento da narrativa da $4^{\mathrm{a}} \mathrm{AS}-\mathrm{GF} 2$.

É como se o coletivo encaminhasse a discussão na direção de tentar responder: o que é viabilizar direitos? Nessa busca, as assistentes sociais enumeram suas atividades, destacando as ferramentas que utilizam no cotidiano. É oportuno destacar a insuprimibilidade ontológica, da categoria cotidiano apontada por Netto (1987), uma vez que [...] na ótica lukacsiana, a vida cotidiana é insuprimível. Não há sociedade sem cotidianidade, não há homem sem vida cotidiana. Nessa perspectiva, Netto (1987) destaca que o cotidiano,

[...] enquanto "espaço-tempo de constituição, produção e reprodução do ser social, a vida cotidiana é ineliminável. [...] se em toda sociedade existe e se põe a cotidianidade, em cada uma delas a estrutura da vida cotidiana é distinta, quanto ao seu âmbito, aos seus ritmos e regularidades e aos comportamentos diferenciados dos sujeitos coletivos (grupos, classes) em face da cotidianidade (NETTO, 1987, p. 65).

Contudo, uma das participantes do estudo, aceita o desafio e elenca um conjunto de ações, mas o faz com a explícita intenção de apreender os sentidos de suas ações. O trabalho das assistentes sociais é analisado na perspectiva de Marx (2006), conforme já assinalado, que o considera como atividade fundamental do homem.

O primeiro tema abordado no grupo focal referiu-se aos dois trabalhos principais que as assistentes sociais realizam nas instituições públicas de saúde de Média Complexidade em função de serem considerados pelas participantes do estudo como trabalhos importantes à medida que permitem "a democratização de informações ao usuário, o empoderamento e a materialização daquilo que a gente [assistente social] se comprometeu com o nosso Projeto Ético Político" (Fragmento da narrativa da $1^{\text {a }}$ AS- GF1).

A discussão remete à necessidade de refletir e aprofundar o conhecimento sobre os múltiplos aspectos que estão presentes na Política de Saúde de forma a buscar compreender o lugar que o trabalho ocupa na Média Complexidade. Nessa alusão ao Projeto Ético Político a profissional, participante da pesquisa remete "a tensão entre projeto ético-político e alienação do trabalho, indissociável do estatuto assalariado" (IAMAMOTO, 2008). Refere-se ainda às "particulares condições do trabalho do assistente social, o clássico dilema entre causalidade e Barbarói, Santa Cruz do Sul, n. 56, p.<22-43>,jan./jun. 2020 
teleologia, entre momentos de estrutura e momentos de ação, exigindo articular, na análise histórica, estrutura e ação do sujeito" (IAMAMOTO, 2009, p. 32).

O trabalho da assistente social nos serviços de saúde de Média Complexidade, conforme relatado pelas participantes da pesquisa, tem sido realizado com o objetivo de viabilizar os direitos da população usuária tendo como base os Parâmetros de Atuação do Assistente Social na Saúde (2014), como destacam as profissionais:

\begin{abstract}
Os dois principais são os dois eixos, [...] o eixo socioassistencial e o eixo socioeducativo que é como a 2. ${ }^{a}$ AS falou, [...] então, são as rodas de conversa com os usuários, e os encaminhamentos socioassistenciais e eles são importantes porque são eles que permitem a democratização de informações ao usuário, o empoderamento e a materialização daquilo que a gente se comprometeu com o nosso Projeto ÉticoPolítico. [...] Então, as atividades socioeducativas e as ações de encaminhamento para rede por permitir o empoderamento do usuário.

Fragmento da narrativa da $1^{\mathrm{a}} \mathrm{AS}-\mathrm{GF} 1$.
\end{abstract}

E os trabalhos mais importantes que [...] é a questão mesmo de estar viabilizando os exames dos pacientes, os exames de alta complexidade que tem lá. Chega ressonância magnética, tomografia de urgência.

Fragmento da narrativa da $4^{\mathrm{a}} \mathrm{AS}-\mathrm{GF} 1$.

As narrativas das participantes corroboram com as concepções previstas nos Parâmetros de Atuação do Assistente Social na Saúde (2014, p. 14), conforme mencionado, as mesmas identificam o trabalho do profissional articulado em quatro eixos de ação, a saber: ações de atendimento direto aos usuários; ações de mobilização, participação e controle social; ações de investigação, planejamento e gestão; ações de assessoria, qualificação e formação profissional. No eixo de atendimento direto aos usuários, se estabelecem as ações socioassistenciais e socioeducativas, sendo perceptível nas suas narrativas, que esses eixos estão presentes no conjunto dos cenários referidos pelas protagonistas do trabalho.

É fundamental reconhecer que tanto no plantão social, quanto nos demais espaços nos quais o assistente social realiza seu trabalho na saúde, ou, no caso desse estudo, nos espaços da Média Complexidade "são incontáveis as possibilidades para a realização de ações socioeducativas. Essas possibilidades se multiplicam quando se considera a diversidade de espaços em que circulam os assistentes sociais" (MIOTO, 2009, p. 507). Todavia, inúmeras foram as situações nas quais as narrativas das profissionais privilegiaram o uso da expressão “as ações repetitivas", remetendo a dimensão do agir profissional imediato, em detrimento do caráter processual de suas ações e análises.

Refletindo sobre esse fato, Mioto (2009) destaca que se pode afirmar que as ações socioeducativas, "realizadas no âmbito dos processos socioassistenciais criam condições para que o profissional elabore, de maneira crítica e consciente, sua própria concepção de mundo e que participe ativamente na produção da história do mundo construindo uma nova cultura" 
(MIOTO, 2009, p. 497). Façamos uma aproximação desse processo de intervenção do assistente social através da narrativa de uma das participantes do primeiro grupo focal.

[...] essas ações socioeducativas eu realizo na sala de espera onde os usuários estão aguardando $o$ atendimento.

Fragmento da narrativa da $1^{\text {a }}$ AS-GF1.

[...] No âmbito das ações socioeducativas tem o trabalho de democratização de informações sobre os serviços, [...] que vai muito na linha do que $2^{\text {a }}$ AS falou: na orientação ao usuário que se dá tanto a partir de ações de roda de conversa,[...] como a partir do próprio ato da entrevista social, do acolhimento ao usuário. A partir do diálogo você identifica quais são as demandas colocadas e quais são os benefícios e os direitos socioassistenciais que o usuário demanda, [...] e eu oriento a esse respeito. Então, as demandas socioeducativas e as socioassistenciais são muito imbricadas. Fragmento da narrativa da $1^{\mathrm{a}} \mathrm{AS}-\mathrm{GF} 1$.

Observemos que na narrativa da $1^{\mathrm{a}} \mathrm{AS}$ - GF1 em dois momentos do grupo ela reitera o caráter articulado e indissociável entre as demandas socioeducativas e as demandas socioassistenciais no trabalho da assistente social, ou seja, assinala o reconhecimento de que as situações vividas pela população usuária precisam ser compreendidas na sua relação intrínseca com as suas necessidades em saúde.

Nessa perspectiva, enfatiza que o profissional do Serviço Social, nesse nível de complexidade, precisa [re]convocar conhecimentos de diversos campos do saber, tendo no horizonte que essa compreensão é condição necessária, mas não suficiente para bem realizar $\boldsymbol{o}$ seu trabalho, uma vez que o nível de compreensão é requisitado, para melhor precisar o imperativo ético, da ação a ser efetivada.

Entendemos que é requerido do profissional, que esse conhecimento se alie à produção de ações que vão desde o acolher as múltiplas necessidades dos usuários, até o de orientá-los sobre seus direitos, com base na apreensão que a profissional assistente social empreende no ato de dialogar sobre sua vida e sobre suas necessidades. Contudo, esse fazer deve estar mediado pela acolhida e pelo respeito às necessidades do usuário e de sua família e aos obstáculos à obtenção da atenção à Saúde que demanda aos serviços de Saúde ou de outras políticas sociais às quais o assistente social requisitará o estabelecimento de relações de cooperação ou a pactuação de compromissos para a criação de uma pauta de cuidados (JOAZEIRO, 2002, p. 136) compartilhados.

Esses saberes são amealhados na constância da vivência dessas relações de estabelecimento de "pautas de cuidados" definidas entre as diversas equipes de cuidado [...] e as equipes do município [...] do doente ou de sua família (JOAZEIRO, 2008, p. 107).

Há que se destacar que as assistentes sociais afirmaram que realizam o seu trabalho, não só com base na apreensão da necessidade que está adstrita a sua esfera de saber e de poder, mas 
também nas situações que extrapolam o seu serviço e implicam na necessidade premente do estabelecimento de relações de compromisso que demandam à Rede de Atenção à Saúde do município, seja ela da Atenção Básica, da Média ou da Alta Complexidade.

[...] Vou dar o exemplo da zika vírus porque foi um boom, um mosquito que causou
um problema desse: a microcefalia. Uma doença, uma patologia mesmo. O que
aconteceu é que a média [complexidade] encheu de crianças com microcefalia e saiu
lá direto para a média [complexidade]. Não teve base. O que era para ser feito na
forma de evitar isso [na atenção básica], não foi feito e a microcefalia foi
um boom nacional. Você pode ver que não é só um problema da criança em si, tem
uma mãe fora do mercado de trabalho, tem mais benefícios, a demanda vai ficando
maior, da Média [complexidade] vai para a Alta [complexidade]
Fragmento da narrativa da $2^{a}$ AS-GF1.

Segundo a análise de Mioto e Nogueira e (2009, p. 282), o Serviço Social no campo da Saúde para construir a integralidade e a participação social em saúde utiliza "três processos básicos, dialeticamente articulados", que as autoras denominam como processos políticoorganizativos, processos de planejamento e gestão e processos socioassistenciais. Segundo elas, a articulação entre esses três processos é que permitirá o estabelecimento do "trânsito tanto entre os diferentes níveis de atenção em saúde, quanto entre as necessidades individuais e coletivas, à medida que as ações profissionais estão, direta ou indiretamente, presentes em todos os níveis de atenção e de gestão" (MIOTO, NOGUEIRA, 2009, p. 282).

Dando continuidade à análise sobre o trabalho do assistente social, a quinta participante do primeiro grupo focal afirma que seu trabalho é viabilizar consultas e exames, e ressalta ainda as limitações da quantidade de consultas, resultando assim na demanda reprimida, conforme segue:

Então, [...] o nosso principal trabalho lá mesmo, é viabilizar as consultas e exames dos pacientes que nos procuram. E a gente tenta, porque é como eu falei, as consultas são limitadas, não tem: "Pagou aqui e eu vou me consultar". Não! A gente sabe.

Fragmento da narrativa da $5^{\mathrm{a}} \mathrm{AS}-\mathrm{GF} 1$.

A narrativa da participante da pesquisa reitera a concepção de Costa (2009) sobre a demanda reprimida e a capacidade real e potencial de oferta "[...] junta-se a cultura institucional hospitalocêntrica e a hegemonia do saber/poder médico, bem como os interesses corporativos de instituições, profissionais e gestores dentro e fora do sistema de saúde" (COSTA, 2009, p. $313)$.

Em outro momento da pesquisa, na resposta ao questionário a assistente social reforça que a demanda reprimida é um obstáculo ao seu trabalho, pois "um dos principais limites é a carência de instrumentos que facilitem o trabalho; a demanda reprimida dos serviços, consultas e exames disponíveis não atende às necessidades dos usuários. Isso ocorre porque o número de 
médicos é limitado", apreende-se em sua narrativa que a oferta de serviços não consegue atender as necessidades da população.

Tabela 1 - População residente, por sexo e zona urbana e rural em Timon, MA. 1991, 2000 e 2010.

\begin{tabular}{|c|c|c|c|c|c|c|}
\hline \multirow{2}{*}{ POPULAÇÃO } & \multicolumn{2}{|c|}{1991} & \multicolumn{2}{|c|}{2000} & \multicolumn{2}{|c|}{2010} \\
\hline & $\mathbf{N}^{\mathbf{o}}$ & $\%$ & $\mathbf{N}^{\mathbf{o}}$ & $\%$ & $\mathbf{N}^{\circ}$ & $\%$ \\
\hline TOTAL & 107.439 & 100,00 & 129.692 & 100,00 & 155.460 & 100,00 \\
\hline Residente Masculina & 52.091 & 48,48 & 63.042 & 48,61 & 75.561 & 48,60 \\
\hline Residente Feminina & 55.348 & 51,52 & 66.650 & 51,39 & 79.899 & 51,40 \\
\hline Urbana & 90.814 & 84,53 & 113.066 & 87,18 & 135.133 & 86,92 \\
\hline Rural & 16.625 & 15,47 & 16.626 & 12,82 & 20.327 & 13,08 \\
\hline
\end{tabular}

Fonte: PNUD, IPEA e FJP.

Esta afirmativa corrobora com os estudos de Costa (2009, p. 312), ao afirmar que "a rede ambulatorial e hospitalar geral e especializada também tem aumento de demanda sem a equivalente ampliação das equipes e da capacidade operacional". Cumpre acrescentar que o município de Timon tem investido nas especialidades médicas e no vínculo estatutário, mas a população cresce constantemente, conforme apontada na Tabela 1, e a oferta de serviços de Média Complexidade não cresce na mesma proporção que a população timonense.

Com relação à limitação de consultas e exames, Costa (2009), no seu estudo de mestrado no qual analisou o Sistema Único de Saúde em Natal, RN, enfatiza que "verifica-se verdadeiros esquemas de drenagem de serviços e procedimentos de alto custo da rede pública para a rede privada e/ou filantrópica conveniada" (COSTA, 2009, p. 313) ao tratar da demanda reprimida, destaca que é notório a mercantilização da saúde, ao transferir para a rede privada um serviço que é dever do Estado e que deveria ser ofertado, por meio de serviços públicos de saúde.

O trabalho do assistente social está ancorado nos princípios previstos no Código de Ética Profissional do Assistente Social, de 1993. Dentre os princípios que norteiam a intervenção profissional do assistente social, destacam-se dois essenciais no desenvolvimento do trabalho nas instituições, o primeiro que reconhece a liberdade como valor ético central e o décimo que trata do compromisso com a qualidade dos serviços prestados à população usuária. Esses são eixos essenciais no processo de deciframento da realidade concreta, na apreensão das necessidades dos usuários e na busca da efetivação de uma intervenção realizada em consonância com suas necessidades. 
$\mathrm{Na}$ resposta ao questionário de uma das assistentes sociais, é destacada a importância do trabalho na esfera da Média Complexidade, a mesma busca colocar em palavras o modo como realiza a acolhida e o encaminhamento do usuário no seu serviço, destaca que sua intervenção é realizada visando a garantia de direitos,

\begin{abstract}
Faço o acolhimento preenchendo fichas que traçam o perfil do mesmo e encaminho para as terapias indicadas pelos médicos especialistas. As minhas ações têm cunho socioeducativo. Como diz, a nossa Iamamoto, tornando possível o acesso aos direitos e meios de exercê-los, como também contribui na defesa e ampliação dos direitos, afirmando compromisso com os direitos e interesses dos usuários, em especial no meu caso, pessoas com deficiência.
\end{abstract}

Assim, ao retomar o pensamento de Iamamoto (2008), reitera seu compromisso com os princípios éticos da profissão materializadas em ações pautadas nos Parâmetros de Atuação do Assistente Social na Saúde. Destaca que suas ações são de cunho socioeducativo, tendo no horizonte a garantia de direitos dos usuários. Na análise a seguir, a profissional revela no fragmento que o trabalho desenvolvido nos níveis de Média e Alta Complexidade, não teria diferenciação, já que destaca a semelhança dos desafios postos em ambos os níveis.

[...] eu falei também um pouquinho do privado, eu trabalho [na] Alta Complexidade
e trabalho na Média Complexidade que é aqui [...]. Os trabalhos são muito parecidos,
não há muita diferenciação da Média para Alta, em termos [do] nosso trabalho, pode
ser que exista nas outras áreas. Não tem muita diferenciação das duas, são muito
parecidos os trabalhos, assim, se eu for para Atenção Básica, vai mudar? Eu acredito
que não, acredito que a gente pode trabalhar com público diferente, mas a viabilização
de direitos, encaminhamento, orientações praticamente são as mesmas. Pode ser que
o modo da gente trabalhar seja diferente em termos de usuário, mas no nível de Média
Complexidade eu não vejo muita diferença não. O meu trabalho é praticamente o
mesmo. Os mesmos profissionais, a rede, a equipe multiprofissional que é
diferenciada, aqui é uma [...], lá é outra [...] totalmente diferente.
Fragmento da narrativa da $2^{\text {a }}$ AS-GF1.

Vejamos a concepção do trabalho do assistente social expressa por Iamamoto (2008) que assinala que um dos elementos constitutivos do processo de trabalho é o trabalho enquanto atividade humana, isto é, a força de trabalho em ação é o elemento vivo e subjetivo do processo de trabalho. Assim sendo, mesmo em níveis de complexidade diferentes o assistente social tem o direcionamento de sua atuação, conforme analisa a autora. A participante da pesquisa destaca que não tem distinção entre o trabalho do assistente social na Média e na Alta Complexidade, uma vez que, na sua perspectiva analítica, o sentido do trabalho profissional seria o de viabilizar direitos para os usuários.

Quando as participantes da pesquisa se referem ao trabalho que realizam para viabilizar acessos à Rede de Atenção à Saúde (RAS) explicitam que essa articulação tem sido efetivada através do uso de encaminhamentos gerados na constância da intervenção profissional das assistentes sociais, 
[...] aí a gente acaba discutindo também outras questões sobre o acolhimento, sobre como funciona o manejo do trabalho, conhecendo a rede, sobre conhecer a rede de atenção materno-infantil, quais foram às mudanças que aconteceram na rede. $\mathrm{O}$ [refere-se a um dos hospitais públicos do município] não está mais fazendo o prénatal, como é que vai ser agora? Apresentar o próprio serviço do CAEMI, tirar dúvidas sobre onde e como se faz esses exames para conhecer a rede mesmo. A gente tem um grande problema que é o trabalho em rede, que é um desafio. A gente quando fala da política de saúde, é um trabalho em rede, e isso é muito difícil para gente costurar.

Fragmento da narrativa da $1^{\mathrm{a}} \mathrm{AS}-\mathrm{GF} 1$.

A profissional aborda o desafio que tem para mapear a rede de serviços de saúdematerno-infantil, destacando que os profissionais e os usuários dos serviços não conhecem a rede de atendimento. E conclui que está "com um desafio agora que é construir, fazer o mapeamento dessa rede". E, na sequência assinala que "é muito difícil porque os próprios profissionais não conhecem a rede e aí imagine o usuário! E o usuário se perde nessa rede, a rede é muito personalizada..." (1 $\left.1^{\mathrm{a}} \mathrm{AS}-\mathrm{GF} 1\right)$.

A rede de atenção se estabelece no "território vivido" (SANTOS, 2006), sendo necessário, continuadamente, o estabelecimento de uma relação da assistente social com os demais profissionais das instituições, com vistas a superar os desafios da fragilidade do fluxo na rede visando consolidar concretamente a articulação entre e na rede supracitada.

Ainda com relação ao trabalho do assistente social na Média Complexidade, a “decifração da realidade" (IAMAMOTO, 2008, p. 28) materializa-se sob a forma da constante busca de "desvendar" as aparências e alcançar a essência da questão social. Nessa perspectiva, as assistentes sociais, ao descreverem o seu trabalho na atenção em nível de Média Complexidade, evidenciaram que para efetivar o cuidado em saúde, tem sido intensa a interlocução com o conjunto das profissões na Rede de Atenção à Saúde e da Rede das demais políticas públicas ou não.

Nesta contínua busca para desvendar a realidade, a narrativa da assistente social revela que, por exemplo, a falta de realização de exames de citologia pelas mulheres atendidas no serviço especializado, traz sérias consequências tanto para a vida da mulher, quanto para a vida da família, uma vez que a falta de ações preventivas e do cuidado da mulher com sua saúde pode resultar em doenças mais graves, como o câncer, como destacado no fragmento abaixo:

Essas mulheres não têm feito citologia. Têm gestantes aqui que a gente pergunta quando foi sua última citologia? E tem umas que estão com seis anos que fizeram a última citologia e está com dois partos recentes, um parto recente. Então, essas mulheres não estão fazendo exames citopatológicos mesmo durante a gestação ou depois da gestação. Então, elas não estão. E por que não estão? Quando elas chegam para gente no [declina o nome da instituição], elas já chegam com lesões, quando aparecem os sintomas já está num nível bem [elevado]

Fragmento da narrativa da $1^{\mathrm{a}} \mathrm{AS}-\mathrm{DG}$. 
A profissional expressa sua preocupação pela ausência da realização dessa ação preventiva de realizar os exames, para evitar que a mesma mulher possa vir a acessar o serviço especializado já com uma lesão indicativa de câncer de colo do útero. Outro aspecto importante, relacionado ao trabalho do assistente social na Média Complexidade é apontado pela mesma participante do grupo focal referente a outra instituição,

\begin{abstract}
[...] como lá é com gestantes, as discussões também são vinculadas ao processo de gestação, são os direitos sociais das gestantes, não só daqueles vinculados ao Programa Bolsa Família, o benefício variável gestante nutriz, mas a questão do benefício ligado ao segurado especial da previdência ou aqueles que não são segurados. A gente trabalha com pouquíssimos segurados, a maioria das mulheres que [...] o perfil das mulheres são de mulheres em condição de vulnerabilidade social sem vínculo empregatício, a maioria é beneficiária do Programa Bolsa Família [...].

Fragmento da narrativa da $1^{\mathrm{a}}$ AS-DG.
\end{abstract}

Apreende-se que a análise da realidade, que as profissionais desse nível de complexidade realizam, pressupõe um conhecimento específico do Serviço Social, que transita entre a compreensão da relação entre agravos à saúde, nosologia, uso de tecnologias da saúde, terapêuticas, prognósticos e de sua relação com os Determinantes Sociais em Saúde (DSS). Implica ainda na orientação sobre as condições de acesso aos serviços e benefícios sociais da política de Seguridade Social - Saúde, Previdência e Assistência Social, bem como do acesso às demais políticas do e no território.

A narrativa de uma participante do estudo reitera que a sua competência profissional como assistente social reside na capacidade de discutir sobre esses direitos com as usuárias mulheres. Alude às palavras de Campos (2000) sobre núcleo de saber, que nesse depoimento, almeja explicitar o que é específico do núcleo de saber do Serviço Social.

\title{
Questão social e vulnerabilidade social no trabalho do assistente social
}

Netto (2006) afirma que é só a partir da concretização das possibilidades econômicosociais e políticas segregadas no estágio dos monopólios que a questão social se põe como alvo de políticas sociais. O significado social da profissão é uma categoria historicamente determinada, cuja compreensão implica o conhecimento da dinâmica estrutural e conjuntural. Assim sendo, para compreender o significado social da profissão,

[...] é preciso ultrapassar a análise do Serviço Social em si mesmo para situá-lo no contexto de relações mais amplas que constituem a sociedade capitalista, particularmente, no âmbito das respostas que esta sociedade e o Estado constroem, frente à questão social e às suas manifestações, em múltiplas dimensões (YAZBEK, 2009, p. 127).

A questão social, matéria-prima do trabalho do assistente social, está presente nas narrativas nos grupos e nas respostas aos questionários. Essa reiterada alusão à vulnerabilidade 
social é uma marca inelutável na pesquisa, uma vez que as protagonistas do trabalho traziam da memória, em seus depoimentos, as múltiplas formas de vulnerabilidade e de risco social que atravessam os seus cotidianos de trabalho, revelando que os Determinantes Sociais da Saúde ampliam os desafios para o cuidado nessa esfera de intervenção, nesse contexto marcado por múltiplas expressões da questão social.

A questão do agravo à saúde é trazida pelas participantes da pesquisa associada às situações de vulnerabilidade social, conforme registro de suas respostas nos questionários:

\begin{abstract}
Pessoas com estado de vulnerabilidade social, em todos os aspectos, saúde, educação, moradia, nutrição, problema sério, desemprego, sendo que todos esses aspectos contribuem para evolução de doenças no indivíduo como um todo. (4 $\left.4^{\mathrm{a}} \mathrm{AS}-\mathrm{Q}\right)$
\end{abstract}

Pobreza, desemprego, insegurança alimentar, violência (com recortes - gêneros), analfabetismo e /ou baixa escolaridade, acesso precário ao trabalho, insegurança habitacional, dentre outros. $\left(1^{\mathrm{a}}\right.$ AS-Q)

A situação de desemprego prevalece nas respostas, seguida da vulnerabilidade social, pobreza, violência e aspectos relacionados aos vínculos familiares e violência. A vulnerabilidade social é ressaltada por quatro profissionais.

Ancoradas na reflexão de Iamamoto (2008) da questão social apreendida como "o conjunto de problemas políticos, sociais e econômicos que o surgimento da classe operária impôs no curso da constituição da sociedade capitalista", as narrativas das assistentes sociais revelam à concepção da autora, e as suas expressões se manifestam diretamente nos serviços de saúde nas quais as profissionais atuam e cotidianamente buscam estratégias para seu enfrentamento. Ainda, percebe-se na fala de uma das profissionais a concepção de pobreza ao se referir à vulnerabilidade social.

Essa discussão remete ao conceito de necessidades humanas básicas e de necessidades de saúde, bem como aos Determinantes Sociais da Saúde (DSS), sendo importante perceber que as assistentes sociais consideram os DSS, ao relacionar a questão social com os fatores sociais mais amplos e vinculados a outras políticas sociais públicas transversais à política de saúde. Tendo em vista que a questão social, sob a forma dos Determinantes Sociais da Saúde tem um importante papel na condição de saúde-doença da população usuária desses serviços de saúde.

No que diz respeito à vulnerabilidade social, as assistentes sociais, no decorrer dos grupos focais, destacaram explicitamente esta categoria como marcante no processo de desenvolvimento de seu trabalho e o reconhecimento dessa vulnerabilidade se materializa sob a forma da discussão do perfil dos usuários a quem se destina suas ações, conforme segue no fragmento: 
Você se depara com usuários que estão em condições de vulnerabilidade e você liga para Gerência de Proteção Básica e não tem recursos para benefício eventual, por exemplo. Então, você olha para o usuário que disse que o último arroz fez ontem e você tem que acolher e desejar força e... Porque acaba sendo uma coisa nesse sentido, mas você acaba fazendo um trabalho mesmo que uma escuta reflexiva, qualificada, de acolhimento enquanto pessoa, enquanto profissional. Então, ao mesmo tempo que você acolhe, e dá essa relação, você tem que falar também de direitos e dizer que é um direito, tem que falar do cenário. Um cenário realmente dificílimo e a tendência é que piore. Então, tem sido, é muito desafiador acolher o usuário, empoderar ele, dar uma autonomia para ele em relação a andar com as próprias pernas e ir atrás dos direitos e, ao mesmo tempo, dizer que esse direito está sendo cerceado, antes de ser garantido porque não tem o serviço e o benefício não existe.

Fragmento da narrativa da $1^{\mathrm{a}} \mathrm{AS}-\mathrm{GF} 1$.

A condição de vulnerabilidade social existe, e a profissional tem o compromisso de esclarecer para o usuário as suas possibilidades de intervenção, conforme preconiza o Código de Ética do Assistente Social. No fragmento "um cenário realmente dificílimo e a tendência é que piore" à alusão da profissional aos efeitos da ampliação da desproteção social, da fragilização das fontes de custeio das políticas sociais e da regressão de direitos. A assistente social reforça o caráter desafiador de trabalhar nessa perspectiva de, por um lado, empoderar o usuário, esclarecer sobre seus direitos e, por outro lado, informá-lo que seu direito não será garantido. Remonta mais uma vez a dupla vinculação e o caráter contraditório da profissão, que esbarra nos limites institucionais, conjunturais e estruturais.

\section{Saúde, Território e Questão social}

As participantes do estudo, ao abordarem as múltiplas formas de vulnerabilidade social tendem a tecer relação com a dinâmica territorial do município de Timon, o qual ocupa um território de 1.764,612 km² (IBGE), que se situa no Estado do Maranhão, na Mesorregião Leste Maranhense - Microrregião Geográfica de Caxias, tendo como limites: ao norte, o município de Caxias e Matões; ao Sul, o Rio Parnaíba e o município de Teresina, capital do Estado do Piauí; ao leste, o município de Caxias; a oeste, o município de Matões (TIMON, 2018-2021). O município é a sede da Região de Saúde de Timon, que é composta pelos seguintes municípios: Timon, Parnarama, São Francisco do Maranhão e Matões. Timon faz parte da Região Integrada de Desenvolvimento da Grande Teresina ( $\operatorname{RIDE}^{4}$ Grande Teresina), sendo Timon o segundo maior município dessa Região.

O município conta com cinco CRAS, sendo que, em consonância com a Política Nacional de Assistência Social (PNAS), cada CRAS deve atender a 5.000 famílias do território e os dados nos apresentam que o município de Timon tem 155.460 habitantes (IBGE, 2010).

\footnotetext{
${ }^{4}$ Criada através do Decreto No 4.367, de 09 de setembro de 2002.

Barbarói, Santa Cruz do Sul, n. 56, p.<22-43>, jan./jun. 2020
} 
Nas narrativas, as participantes do grupo referem que a quantidade de CRAS, que compõe a Rede de Assistência Social não consegue atender as famílias em situação de vulnerabilidade social, que corresponde a 34.784 famílias (BRASIL, 2019). São famílias que vivem em condição de pobreza e de extrema pobreza, que tiveram seus direitos negados e estão impedidas de viver em condições dignas, situação essa que é agravada pela problemática de saúde.

\begin{abstract}
Então, eu vejo, nessa perspectiva de trabalhar os aspectos sociais, que é importante que se considere [...] os aspectos sociais no processo saúde-doença, romper com essa questão só do biológico-curativo. Já está com outro modelo de enfrentamento e eu acho que considerar o social é muito importante porque rebate diretamente no usuário que ele não tem o que comer, ele não tem como sair de casa para ir para uma consulta, ele não tem... O usuário que chega para mim e diz o último arroz eu fiz ontem, ele está com as taxas alteradas de diabetes, de hipertensão, não adere ao tratamento. Eu não posso categorizar esse usuário como um usuário teimoso, um usuário que não é sensível a causa dele. Que condições objetivas esse usuário tem de comer bem? De fazer uma dieta como a nutricionista prescreveu? Que o médico orientou ou usar a medicação?... Que nível de compreensão ele tem? Que escolaridade ele... para ele entender aquele manejo? Aquelas questões que o médico colocou, não é? Então, eu vejo nesse sentido que faz sim a diferença, não é?

Fragmento da narrativa da $1^{\mathrm{a}} \mathrm{AS}-\mathrm{DG}$.
\end{abstract}

No fragmento a assistente social se refere a uma situação recorrente no cotidiano profissional, que remete à vulnerabilidade social vivenciada pelos usuários da política de saúde. Nas histórias de vidas narradas às profissionais, buscam na memória (Bosi, 2003) não a história cronológica, narram "outra história mais densa de substância memorativa no fluxo do tempo" (op. cit., p. 11). É no "território vivido" (SANTOS, 2006) que estas famílias estabelecem suas relações sociais, se utilizam e acessam as políticas públicas de Saúde, de Assistência Social, Habitação, Educação, dentre outras disponíveis no território de Timon.

Essa discussão tecida nos grupos remete à questão da intersetorialidade das políticas sociais, uma vez que os usuários que buscam os serviços de saúde necessitam, muitas vezes, ter acesso aos benefícios na Rede Socioassistencial. Afirma uma participante do estudo, que "o usuário que chega para mim e diz o último arroz eu fiz ontem [...]" (Fragmento da narrativa da $1^{\text {a }}$ AS-DG), precisará buscar os meios para atender suas necessidades de saúde e também as de sobrevivência.

Nesse contexto, outra assistente social do segundo grupo focal explicita a importância dos Determinantes Sociais da Saúde no processo saúde-doença, ao reconhecer que as situações de erisipela em que "não é só um carocinho, aí cresce e fica meio avermelhado [...] com calor no local, isso é rotineiro, os ferimentos infectados maltratados em casa" (Fragmento da narrativa da $\left.3^{\mathrm{a}} \mathrm{AS}-\mathrm{GF} 2\right)$. Assim, segue relacionando essa doença com os Determinantes Sociais da Saúde, ao remeter a vulnerabilidade social sob diferentes aspectos, pois "às vezes até por falta de uma alimentação adequada, tomar água, tomar bastante líquido, higienização" 
(Fragmento da narrativa da $3^{\mathrm{a}}$ AS-GF2) constituem-se em limites objetivos para a recuperação da saúde.

No que tange aos Determinantes Sociais da Saúde e a sua relação com o processo saúdedoença, a $1^{\mathrm{a}}$ AS enfatiza que "as principais demandas apresentadas decorrem da condição de vulnerabilidade social vivenciada pelas usuárias e que rebatem direto no processo saúdedoença", a saber, "insegurança alimentar e renda, desemprego, baixo ou precário acesso a serviço da rede intersetorial, dentre outros correlatos", isto é, a insegurança alimentar e de renda, geradas muitas vezes pelo desemprego são apontados pelas participantes como Determinantes Sociais da Saúde muito presentes na dinâmica de seus atendimentos na Média Complexidade que interferem diretamente no processo saúde-doença dos usuários do SUS.

As narrativas das assistentes sociais reafirmam o que apontam Mioto e Nogueira (2009, p. 229), que os fatores relacionados aos "[...] níveis de ocupação, renda, acesso à educação formal e ao lazer, os graus de liberdade, hábitos e formas de relacionamentos interpessoais, a possibilidade de acesso aos serviços voltados para a promoção e recuperação da saúde [...]”, expressam os determinantes das condições de saúde da população.

Interessante enfatizar a reflexão da segunda assistente social no grupo focal, que tratou da questão do processo saúde-doença e do olhar diferenciado da profissional de Serviço Social em comparação com o dos médicos e enfermeiros, a saber:

[...] a gente estuda uma coisa e a Medicina estuda outra. Essa parte de saúde-doença está muito ligada com médicos e enfermeiros. A gente já tem outro entendimento, apesar da gente ser uma profissão que chegou muito mais tarde na saúde.

Fragmento da narrativa da $2^{\mathrm{a}}$ AS-GF1.

No fragmento, a profissional afirma que o saber do assistente social, ou seja, da profisssão é mais recente na área da saúde, que segundo Bravo e Matos (2007), a inserção do assistente social na política de saúde se dá na década de 1940. Registra-se que em outro momento do grupo emerge a discussão sobre vulnerabilidade social,

[...] A gente faz a visita aos nossos pacientes, a maioria das vezes, como eu mencionei agora pouco, são pacientes que chegam lá debilitados, [...], com vulnerabilidade social, na maioria das vezes [...] a vulnerabilidade social hoje é completa, [...], e aí dependendo do nosso... da nossa expectativa, a gente vai tentar melhorar, sanar a situação de saúde de cada paciente. A gente visita todos os dias esses pacientes e vê a demanda.

Fragmento da narrativa da $4^{\mathrm{a} A S-G F 2}$.

[...] Às vezes, já aconteceu realmente de chegar pacientes lá e não ter como fazer o exame e a gente orienta [...]. Nessa questão dos orçamentos para poder estar levando lá na Auditoria para a Secretaria arcar, porque isso existe. Outros não tem paciência de esperar, mas aqueles que não têm condições financeiras eles aguardam.

Fragmento da narrativa da $5^{\mathrm{a}} \mathrm{AS}-\mathrm{GF} 2$.

Uma análise atenta às narrativas das participantes dos grupos identifica que elas tentavam construir um perfil dos usuários do SUS, tendo marcado a forte presença de situações Barbarói, Santa Cruz do Sul, n. 56, p.<22-43>,jan./jun. 2020 
de vulnerabilidade social. Esse aspecto se opõe ao acesso universal que o SUS preconiza, uma vez que para o Serviço Social da Saúde na Média Complexidade, tem havido demandas recorrentes ligadas ao entrecruzamento entre as necessidades de saúde e as de vulnerabilidade e de risco social. Ainda se acrescenta a fala de uma das participantes sobre vulnerabilidade social:

\footnotetext{
Hoje mesmo aquele, o marido da dona [declina o nome da usuária], entrou na sala e disse: "Olha, eu quero lhe agradecer. Minha mulher fez o exame, está tudo bem, paguei $R \$ 1.200,00$ pela ressonância, mas eu lhe agradeço muito. A você e outra que estava aqui ontem". Eu falei o teu nome, [refere-se a outra participante]. Aí, ele disse assim: "Muito obrigada por ter nos informado. Para não ficar esperando, para não esperar por um exame que não vai acontecer daqui para segunda-feira, porque o caso da minha esposa é grave e tinha que fazer logo esse exame". Ele pagou R $\$ 1.200,00$ parcelado no [declina o nome de uma instituição bancária] e disse que a família vai ajudar a pagar o exame.

Fragmento da narrativa da $3^{\mathrm{a}} \mathrm{AS}-\mathrm{GF} 2$.
}

Acrescenta ainda que a condição de vulnerabilidade social não impossibilita os usuários de buscarem os serviços privados de saúde, em virtude da urgência de obter respostas para as necessidades de saúde, estes comprometem seus parcos orçamentos, se endividam para tentar acesso a um direito universal, previsto na Carta Constitucional, conforme manifestado pelas participantes no fragmento supracitado.

A questão da premência da necessidade de elucidação do diagnóstico, entendida como um aspecto marcado pela temporalidade do vital entra em confronto com a da temporalidade burocrática e a do relógio, que define fluxos assistenciais que não se coadunam com a temporalidade do vital, marcada pela fragilidade da vida e de seus riscos (JOAZEIRO, 2009). Outro aspecto identificado na narrativa supracitada é a mercantilização dos serviços de saúde desse nível de complexidade, que se vê fortalecida quando o serviço público de Saúde não concede as respostas às necessidades prementes de saúde do cidadão, impelindo-os a recorrer aos serviços privados de saúde.

\section{Considerações finais}

A pesquisa permitiu analisar o trabalho do assistente social nas instituições de saúde de Média Complexidade no município supramencionado, sendo que, a partir da fundamentação teórica e da triangulação de fontes, tendo no horizonte o alcance dos objetivos do estudo, podese perceber que no desenvolvimento de seu trabalho, o assistente social é colocado diante de um conjunto de demandas que, muitas vezes, são marcadas pela tensão entre múltiplas temporalidades. 
Nessa perspectiva, as assistentes sociais marcaram em suas narrativas que, diariamente, são chamadas a intervir num espaço, marcado por múltiplas formas de saberes, contudo, são profundamente tensionadas pela ampliação da demanda de atenção especializada em saúde, cuja oferta está subdimensionada em relação à disponibilidade de vagas de consultas, exames especializados e de leitos hospitalares. Daí a contínua alusão à preocupação gerada no coletivo das assistentes sociais, provocadas pelas demandas assistenciais crescentes e a reduzida oferta de respostas em consonância com as necessidades em saúde desse nível de complexidade.

O estudo revelou que o trabalho do assistente social nesse nível de complexidade, está marcado pela dinâmica de tentar produzir acessos e fluxos mais resolutivos no atendimento na Rede, com vistas a imprimir dinamicidade aos processos de fruição do direito na atenção à saúde na esfera do SUS. Contudo, esse trabalho está marcado de forma inequívoca pelos obstáculos presentes na dinâmica da Rede de Serviços da Média Complexidade, devido a fragilidade do fluxo entre os Serviços da Atenção Básica, Média e da Alta Complexidade da Rede de Atenção à Saúde no Município.

As narrativas das profissionais sobre a questão social e sobre os atendimentos realizados nos serviços de saúde no município apontaram que as assistentes sociais direcionam seu olhar e sua intervenção para as necessidades dos usuários e de seus familiares.

Nessa ótica, o estudo revelou, que as necessidades em saúde da Média Complexidade na sua articulação com as expressões da questão social no universo do atendimento à saúde situam-se para além da doença e do acesso dos usuários a consultas e exames, que são de competência desse nível da atenção especializada, mas coadunam-se com uma marcante presença de obstáculos de descontinuidades presentes nessa Rede associadas ou não às múltiplas expressões da questão social explicitadas ao longo do estudo. Dentre elas destacaram a vulnerabilidade social, o desemprego, a violação do direito às crianças, aos adolescentes e às mulheres vítimas de violência, idosos abandonados, a insegurança alimentar e de renda.

Assim sendo, identificou-se que as assistentes sociais reconhecem nas suas narrativas, a intrínseca relação entre os Determinantes Sociais na Saúde e o processo saúde-doença, ao mesmo tempo que, intentam construir um olhar crítico para o contexto atual do SUS, e o fazem, na perspectiva de compreender as marcas da conjuntura social, política e econômica presentes nas necessidades em saúde dos usuários dos serviços de saúde de Média Complexidade e nos demais níveis de atenção à Saúde.

As assistentes sociais revelaram que as vulnerabilidades decorrentes da questão social incidem na sua atuação profissional na saúde, posto que nela materializa-se sob a forma de múltiplas necessidades, fato que lhes impõe diversificadas formas de gerir o trabalho para o 
enfrentamento dessas expressões da questão social no atendimento às necessidades humanas básicas e de saúde da população. E ao fazê-lo, explicitam que reconhecem o provimento dessas necessidades como direito, e entendem o seu enfrentamento como uma necessidade e uma possiblidade que visa empoderar a população usuária do SUS para a defesa de seus direitos constitucionais. Nesse sentido, o seu trabalho cotidiano está fortemente ligado à questão da luta pelo direito à saúde, a garantia do direito à vida.

\title{
THE WORK OF THE SOCIAL WORKER AND THE INTERVENTION STRATEGIES IN MEDIUM COMPLEXITY HEALTH SERVICES IN TIMON (MARANHAO, BRAZIL)
}

\begin{abstract}
This paper presents an analysis of the work of the social worker and the intervention strategies implemented in the routine of Medium Complexity health services in Timon, state of Maranhão, as well as seeks to understand the social issue and the social vulnerability in the work of this professional in that city. This study is an excerpt of the Master's thesis presented in the Master's Program in Public Policy at the Universidade Federal do Piauí (UFPI). In the methodological path was used the qualitative research, literature analysis, documentary research and field research through the use of focus groups. The participants in this study were five social workers who work at five different public health institutions of Medium Complexity in Timon within the scope of SUS. In the study, the social workers revealed in their narratives that they are daily called to intervene in a space marked by multiple forms of knowledge. However, they are deeply tensioned by the expansion of the demand for specialized health care, whose offer is undersized in relation to the availability of places of medical appointments, specialized exams and hospital beds. The study reveals that the work of the social worker at this level of complexity is deeply marked by the dynamics of trying to produce accesses and more resolutive flows in the service for the patients in the health institutions and in the network, seeking to give dynamism to the fruition processes of the right to health care in the sphere of SUS.
\end{abstract}

Keywords: Work, Social Issues, Secondary Attention.

\section{REFERÊNCIAS}

BOSI, E. O tempo vivo da memória: ensaios de Psicologia Social. São Paulo: Ateliê Editorial, 2003.

BRASIL. Ministério do Desenvolvimento Social e Agrário (MDSA). SAGI. Relatório de Informações Sociais (SAGI). 2019. Disponível em:

https://aplicacoes.mds.gov.br/sagi/RIv3/geral/relatorio.php\#Benefícios. Acesso em: 20 de setembro de 2019.

BRASIL. Ministério do Desenvolvimento Social e Combate à Fome - Secretaria Nacional de Assistência Social. Política Nacional de Assistência Social - PNAS/2004. Brasília, DF:

2005. Disponível em:

http://www.mds.gov.br/webarquivos/publicacao/assistencia_social/Normativas/PNAS2004.pd

f. Acesso em: 22 de setembro de 2017. 
BRAVO, M. I. de S.; MATOS, M. C. de. A saúde no Brasil: reforma sanitária e ofensiva neoliberal. In: BRAVO, M. I. de S. (Org.). Política social e democracia. 2. ed. São Paulo: Cortez, 2007.

CAMPOS, G. W. S. Saúde pública e saúde coletiva: campo e núcleo de saberes e práticas. Ciência Saúde Coletiva [online]. 2000, vol.5, n.2, p. 219-230. Disponível em: http://www.scielo.br/pdf/csc/v5n2/7093.pdf. Acesso em: 18 de setembro de 2017.

CFESS. Código de Ética Profissional do Assistente Social. Brasília, 1993.

CFESS. Parâmetros para Atuação de Assistentes Sociais na Política de Saúde. Brasília, 2014.

COSTA, M. D. H. O trabalho nos Serviços de Saúde e a Inserção dos (as) Assistentes Sociais. IN: MOTA, A. E. et al. (Orgs.). Serviço social e saúde: formação e trabalho profissional. São Paulo: OPAS: OMS: Ministério da Saúde, 2009, p. 304-351.

ELIAS, N. Sobre o tempo. Rio de Janeiro: Zahar, 1998.

FLICK, U. Introdução à pesquisa qualitativa. tradução Joice Elias Costa. 3. ed. Porto Alegre: Artmed, 2009.

GATTI, B. A. Grupo focal na pesquisa em Ciências Sociais e Humanas. Brasília: Liber Livro Editora, 2005.

GIL, A. C. Métodos e Técnicas de Pesquisa Social. 5. ed. 8. reimp. São Paulo: Atlas, 2007.

GOMES, F. F. C. et al. Acesso aos procedimentos de média e alta complexidade no Sistema Único de Saúde: uma questão de judicialização. Cadernos de Saúde Pública. 2014, v. 30, n. 1, pp. 31-43.

IAMAMOTO, M. V. Serviço Social na contemporaneidade: trabalho e formação profissional. São Paulo: Cortez, 2008.

IAMAMOTO, M. V. Os espaços sócio-cupacionais do assistente social. In: Conselho Federal de Serviço Social. Associação Brasileira de Ensino e Pesquisa em Serviço Social. Direitos Sociais e Competências Profissionais. 2009. v.1. p. 341-376.

IBGE. Instituto Brasileiro de Geografia e Estatística. Censo de 2010. Município de Timon. Disponível em: https://cidades.ibge.gov.br/v4/brasil/ma/timon/panorama. Acesso em: 15 de setembro de 2017.

IBGE. POP_IBGE_SINASC_2016IBGE_ESTIMATIVA_2012_SINASC_2014(1). Censo 2010. Ministério da Saúde. Disponível em: https://www.pni.datasus.gov.br/downloads.asp. Acesso em: 18 de setembro de 2017.

JOAZEIRO, E. M. G. Estágio Supervisionado: experiência e conhecimento. Santo André: ESETec, 2002. 
JOAZEIRO, E. M. G. Supervisão de Estágio: formação, saberes, temporalidades. Santo André: ESETec, 2008.

JOAZEIRO, E. M. G. Supervisão Acadêmica e de Campo: relação entre saberes. Teresina: Edufpi, 2018.

MARX, K. O capital: crítica da economia política. Rio de Janeiro: Civilização Brasileira, 2006.

MINAYO, M. C. de S (Org.). Pesquisa Social: Teoria, método e criatividade. 18 ed. Petrópolis: Vozes, 2001.

MIOTO, R. C. T; NOGUEIRA, V. M. R. Desafios Atuais do Sistema Único e Saúde-SUS e as exigências para os Assistentes Sociais. In: MOTA, A. E. et al. Serviço Social e Saúde: formação e trabalho profissional. São Paulo: OPAS: OMS: Ministério da Saúde, 2009.

NETTO, J. P. Capitalismo monopolista e Serviço Social. São Paulo: Cortez, 2006.

NETTO, J. P.; CARVALHO, M. do C. B. Cotidiano: Conhecimento e Crítica. São Paulo: Cortez, 1987.

ROSA, M. I. Usos de si no trabalho e Densificação: nova modalidade. In: FÍGARO, R. (Org.) Gestão da comunicação: no Mundo do Trabalho, Educação, Terceiro Setor e Cooperativismo. São Paulo: Atlas, 2005.

SANTOS, M. O dinheiro e o território. In: SANTOS, M. et al. Território e territórios: ensaios sobre o ordenamento territorial. Rio de Janeiro: DP\&A Editora, 2006, 2.ed, p.13-21.

SILVA, C. R. et al. Dificuldade de acesso a serviços de média complexidade em municípios de pequeno porte: um estudo de caso. Ciência \& Saúde Coletiva. 2017, v. 22, n. 4, pp. 11091120 .

YAZBEK, M. C. O significado sócio-histórico da profissão. In: Conselho Federal de Serviço Social. Associação Brasileira de Ensino e Pesquisa em Serviço Social: Direitos Sociais e Competências Profissionais. Brasília: CFESS/ ABEPSS, 2009. v.1. p. 126-139.

Data de recebimento: 08/03/2020

Data de aceite: $27 / 05 / 2020$

\section{Sobre as autoras:}

Violêta Maria da Silva Nolêto é Mestre em Políticas Públicas pela Universidade Federal do Piauí (UFPI), Especialista em Políticas Públicas para Crianças e Jovens pela UFPI e Graduada em Serviço Social pela UFPI. Assistente Social da Secretaria Municipal de Saúde de Timon (MA) e do Centro de Referência Especializado de Assistência Social (CREAS Norte) de Teresina (PI). Endereço Eletrônico: flower_violeta@ hotmail.com

Edna Maria Goulart Joazeiro é Pós-Doutora em Serviço Social pelo Programa de Estudos PósGraduados em Serviço Social da Pontifícia Universidade Católica de São Paulo (PUC-SP), 
Doutora e Mestre em Educação pela Universidade Estadual de Campinas (UNICAMP). Docente do Departamento de Serviço Social e do Programa de Pós-Graduação em Políticas Públicas da Universidade Federal do Piauí (UFPI) na Linha Cultura, Identidade e Processos Sociais. Líder do Grupo de Estudo e Pesquisa Formação, Trabalho, Desigualdade Social e Políticas Públicas, CNPq, Brasil. Endereço Eletrônico: emgoulart@uol.com.br 